\title{
Limited effects of egg size on chick growth in the chinstrap Penguin Pygoscelis antarctica
}

\begin{abstract}
We studied the effect of egg size on chick growth in the chinstrap penguin under natural nonmanipulative, conditions. The influence of egg size on chick mass at hatching, 15 and 45 days of age was analysed controlling for the effect of hatching date, as hatching date has been repeatedly associated with chick growth in this species. Egg volume explained $20 \%$ of the variation in the body mass of chicks at hatching. Its effect disappeared as chicks grew, being statistically not significant at the age of 15 and 45 days. Egg volume asymmetry also had no role in determining chicks' growth asymmetries.
\end{abstract}

\section{Introduction}

The influence of egg size on fecundity in avian species has been widely documented, especially in seabirds (see Magrath 1992; Croxall et al. 1992; Williams 1994, and references therein). However, there is little unequivocal evidence to date in support of a positive relationship in birds between egg size and fitness (Williams 1994; see nevertheless Bolton 1991; Croxall et al. 1992; Magrath 1992; Amundsen et al. 1996). A benefit is gained by laying large eggs, as large eggs tend to result in large hatchlings (Grant 1991; Amundsen 1995; Amundsen et al. 1996) that experience a faster growth and a higher probability of survival at least during the first days after hatching (Schifferli 1973; Williams 1994; Amundsen 1995). Several studies have also demonstrated egg size to

\section{J. Belliure · L.M. Carrascal ( $₫)$}

Museo Nacional de Ciencias Naturales-CSIC,

J.Gutiérrez Abascal 2,

E-28006 Madrid, Spain

e-mail: mcnc152@fresno.csic.es

E. Minguez $\cdot$ M. Ferrer

Estación Biológica de Doñana-CSIC, Paseo María Luisa S.N., E-41013 Sevilla, Spain be positively related to parental quality (Amundsen and Stokland 1990; Saether 1990; Croxall et al. 1992; Williams 1994; but see Moreno et al. 1994). Therefore, the apparent effect of egg size could be due to either random variation in egg size per se, or to parental quality. Recent experimental studies trying to separate the effects of egg size and parental quality have found an effect of egg size per se at early nestling ages (Amundsen and Stokland 1990; Reid and Boersma 1990; Magrath 1992; Amundsen 1995; Amundsen et al. 1996), and an influence of parental quality on growth and survival at later chick ages (Amundsen and Stokland 1990; Reid and Boersma 1990; Bolton 1991; Magrath 1992).

The aim of this paper is to study the association between egg size and chick growth in the chinstrap penguin (Pygoscelis antarctica) over the whole breeding period. Hatching date has usually been related to parental quality and environmental stress (e.g., weather harshness, food availability) and it has a strong effect on offspring survival (Daan et al. 1988). Based on prior studies with this species where hatching date is negatively associated with chick growth and survival (Moreno et al. 1994; Viñuela et al. 1996; Moreno et al. 1997), we analyse the influence of egg size controlling for the effect of hatching date. We also try to partition the variance in chick growth into those components related to egg size and hatching date to show their relative importance under natural non-manipulative conditions. With this observational non-manipulative approach, we try to define the time lapse when egg size exerts a clear effect on chick growth, and to quantify this effect in order to assist the design of future experiments.

\section{Materials and methods}

The study was conducted at the Vapour Col chinstrap penguin colony (20,000 breeding pairs) on Deception Island, South Shetlands $\left(63^{\circ} 00^{\prime} \mathrm{S}, 60^{\circ} 40^{\prime} \mathrm{W}\right)$, during the breeding season (December/February) of 1995/1996. 
During incubation, we marked 50 nests with numbered sticks. All the nests contained two-egg clutches (the modal clutch size in this species). We tried to visit nests daily before hatching of the chicks, and only those nests where hatching was determined with precision were considered for the study. In order to reduce differences in the parental quality of the sampled nests, we performed the analyses with those nests in which both chicks were raised till at least 45 days of age. Beforehand, we had checked that survival till 45 days of age was not related to egg size $(r=0.05, P>0.05$, $n=50)$. By this sample reduction, we tried to obtain the best conditions to test the role of the egg size per se, under natural non-manipulative conditions, on chick growth in the chinstrap penguin. Final sample size was then 37 nests (13 nests were not considered due to imprecisions in estimation of hatching date, and chick mortality before 45 days of age).

One of the authors (J.B.) measured egg length and maximum width to the nearest $0.01 \mathrm{~mm}$ with digital calipers. Egg volume was calculated according to the formula of Hoyt (1979): volume $=0.51 \times$ length $\times$ width ${ }^{2}$.

Chicks were individually marked with an indelible felt pen. At the age of 17-21 days chicks were banded with standard metallic flipper bands (Lambournes) before the formation of crèches. Chicks were weighed after hatching $(1.0 \pm 0.8$ days $)$, and at the ages of $15(15.4 \pm 0.6)$ and $45(45.2 \pm 2.5)$ days.

The relationship between average egg volume and average body mass at 1,15 and 45 days of age, controlling for the effect of hatching date, was analysed by means of multiple regression analyses. All regression models also included chick age when chicks were measured as an independent variable, to control the effect of inter-clutch differences in chick age due to sampling limitations (e.g. bad weather conditions). The effect size of each independent variable (partial $\eta$ squared) was estimated to quantify the percentage of variance in body mass explained by the egg volume controlling for the effects of chick age when measured and hatching date. The same procedure was used in the study of withinbrood variability in body mass (asymmetry), using chick age when measured, hatching asynchrony and withinclutch variation in egg volume. Asymmetry was estimated as the absolute diference between chicks (body mass) or eggs (volume) divided by the mean and expressed in percentage.

For all analyses, we averaged both nest parameters (egg volume or chick body mass) to avoid the lack of statistical independence associated to members of the same nest. Normality and homocedascity were checked for variables and the residuals of the regression models. All regression analyses were calculated using SPSS 6.0 (Norusis 1992). Means are reported \pm standard deviation (SD). Sequential Bonferroni correction (Rice 1989; Chandler 1995) has been applied to results of statistical tests (two-tailed tests).

\section{Results}

We measured 74 eggs from 37 clutches that hatched. The mean length of the eggs was $67.0 \pm 2.4 \mathrm{~mm}$, and the mean breadth of the eggs was $52.2 \pm 1.6 \mathrm{~mm}$. Egg volume per nest had a mean of $91.5 \pm 8.1 \mathrm{~cm}^{3}$, with a range of $76.9-115.7 \mathrm{~cm}^{3}$ and a coefficient of variation of $8.8 \%$. Of the amount of egg volume variability observed in the 74 eggs of the 37 nests, $90.9 \%$ was accounted for by inter-clutch differences, while $9.1 \%$ was due to intracluch differences in egg volume. Accordingly, intrabrood asymmetry in the egg volume was consistently low: $4.2 \pm 3.2 \%$.

Hatching occurred between 18 and 29 December, with a median hatching date of 22 December (for 37 different nests), and was not associated with egg volume $(r=0.039, n=37, P=0.820)$. Average hatching asynchrony was $0.9 \pm 0.8$ days $(n=37)$, and was not related to within-clutch egg volume asymmetry $(r=$ 0.046, $n=37, P=0.789$ ).

Figure 1 shows the values for body mass of chicks at different ages. In hatchlings (chick age of 1 day), body mass was significantly related to egg volume and to hatching date (Table 1). At the ages of 15 and 45 days, the effects of egg volume and hatching date were not significant (Table 1). The amount of variance explained by egg volume was low during the breeding period (Table 1), decreasing the effect of egg volume with chick age (from $20.3 \%$ when hatchlings to $1.5 \%$ at 45 days). Hatching date explained $43.7 \%$ of the variation in body mass at hatching (Table 1), its effect being not significant at the age of 15 and 45 days.

Within-brood asymmetry in body mass was not significantly affected by within-clutch asymmetry in egg volume at any chick age (Table 1). Hatching asynchrony was only related to within-brood asymmetry in body mass at 15 days of age (Table 1). The percentage of

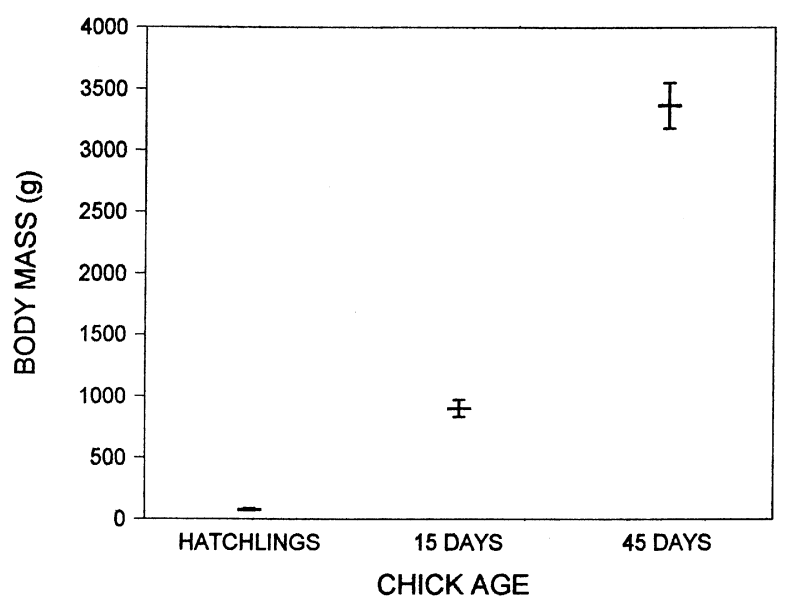

Fig. 1 Variation of mean body mass ( $\pm 99 \%$ confidence interval) of chicks with age. Sample size is 37 nests (averaging the body mass of two chicks per nest) 
Table 1 Multiple regression analyses explaining inter-clutch variation in body mass and within-brood asymmetry in body mass at three different stages of chick growth. Chick age at sampling was also included as an independent variable together with the other variables to control its distorting effect on regression results (see
Materials and methods). The standardised regression coefficients $(\beta)$, their significance levels $(P)$ and the percentage of variance accounted for by each independent variable (\%) are reported. Sample size is 37 in all cases. \# indicates the effects that did not remain significant after the sequential Bonferroni correction

\begin{tabular}{|c|c|c|c|c|c|c|c|c|c|}
\hline & \multicolumn{3}{|c|}{ Hatchlings } & \multicolumn{3}{|c|}{15 days } & \multicolumn{3}{|c|}{45 days } \\
\hline & $\beta$ & $\%$ & $P$ & $\beta$ & $\%$ & $P$ & $\beta$ & $\%$ & $P$ \\
\hline \multicolumn{10}{|l|}{ Body mass } \\
\hline Egg volume & 0.33 & 20.3 & 0.007 & 0.11 & 1.3 & 0.510 & 0.12 & 1.5 & 0.488 \\
\hline Hatching date & 0.57 & 43.7 & 0.000 & 0.09 & 1.0 & 0.566 & -1.11 & 12.9 & $0.034^{\#}$ \\
\hline \multicolumn{10}{|l|}{ Body mass asymmetry } \\
\hline Egg asymmetry & 0.06 & 0.6 & 0.667 & -0.09 & 1.2 & 0.930 & -0.10 & 0.1 & 0.595 \\
\hline Hatching asynchrony & 0.41 & 12.0 & $0.042^{\#}$ & 0.55 & 29.8 & 0.001 & 0.02 & 0.0 & 0.925 \\
\hline
\end{tabular}

variability in body mass asymmetry among different broods explained by within-clutch egg asymmetry was very low $(<2 \%)$, and did not show a clear pattern during chick growth (Table 1).

\section{Discussion}

Average egg volume measured in our study does not differ from the value reported by Moreno et al. (1994) for the chinstrap penguin during the 1991/1992 breeding season in the Vapour Col colony (egg size: $90.1 \mathrm{~cm}^{3}$ as compared to $91.5 \mathrm{~cm}^{3}$ in our study; $t$-test for comparison of an expected mean with the mean of our data series: $t=1.10 ; P=0.28$ ). This lack of difference is also reflected in the percentage of intra-brood asymmetry in the egg volume, as the value of $4.2 \%$ from our study does not significantly differ from the value of $4.4 \%$ reported by Moreno et al. (1994; $t=0.38 ; P=0.71$ ). These results suggest an interannual constancy in the egg size for the chinstrap penguin in the Vapour Col colony.

Egg volume explained a small proportion of the variation in the body mass of chicks, and was only significant immediately after hatching. The existence of a direct association between egg size and hatchling size has also been described in the Magellanic penguin until 10 days after hatching (Reid and Boersma 1990), and this is the most general association found between egg volume and chick size in a large number of studies (Williams 1994; Amundsen 1995; Amundsen et al. 1996). Near fledging, an effect of egg size on chick size was not detected, this result being in general agreement with other studies where chick size at fledging seems independent of egg size (Reid and Boersma 1990; Meathrel et al. 1993; Robertson and Cooke 1993; Smith et al. 1993; Williams et al. 1993; but see Magrath 1992).

Egg volume asymmetry had no role in determining chick growth asymmetries. Hatching asynchrony in altricial birds has been proposed as a strategy to favour the creation of size hierarchies among siblings, which can facilitate brood reduction in cases of food shortage (Lack 1947; Ricklefs 1965; Howe 1978; O'Connor 1978;
Mock 1984). Although hatching asynchrony is one component of size asymmetries in penguins (see a review in Lamey 1990; Williams 1980; Van Heezik and Seddon 1991; Williams and Croxall 1991), the relatively frequent reversal of size hierarchies among chicks in the chinstrap penguin (Moreno et al. 1994) make degree of asynchrony a poor predictor of size asymmetry. In fact, the association found at 15 days of age was absent at hatching and at 45 days of age. Also, in gentoos, reversals in size rank at hatching are frequent and initial asymmetries do not predict asymmetries at 30 and 60 days of age (Williams and Croxall 1991).

The lack of association between hatching date and egg volume was also reported by Moreno et al. (1994) for the chinstrap penguin in the 1991/1992 breeding period at the Vapour Col colony. Hatching date was positively associated with body mass at hatching (later hatched eggs produced larger hatchlings), explaining $44 \%$ of the variation in the body mass, but showed no effect at 15 and 45 days of age. Thus, early-hatched chicks demonstrated a better growth performance. This pattern of association between an early hatching date and a faster chick growth has been repeatedly observed for the chinstrap penguin at the Vapour Col colony in several breeding periods (1991/1992, 1992/1993, and 1993/1994: Viñuela et al. 1996; 1994/1995: Moreno et al. 1997). This fact suggests the existence of important "quality" differences between late- and early-hatching pairs, supporting our analysis design controlling for the hatching date in this non-manipulative study of the effects of egg size on chick growth.

Several factors can be used to explain the lack of importance of egg size on breeding performance of this species. Its limited effect for the first days of life after hatching could not be maintained due to several factors, such as the non-coordination between parents in the allocation of feedings among siblings, the random gain in feedings of different size when chicks are very small, the unpredictability of food availability near the colony, etc. However, if egg composition more than egg volume exerts an influence on chick size (Howe 1978; Meathrel et al. 1993), then the effect of egg size would not be observable, as eggs of similar size could have different 
compositions. Finally, lack of inter-brood variability in egg size could be responsible for the very small effect of egg volume on chicks' growth. This seems not to be the case, as the coefficient of variation of egg volume in this species is similar or higher than those observed for other antarctic seabirds (see Amundsen 1995 for Pagodroma nivea and Amundsen et al. 1996 for Thalasoica antarctica).

Acknowledgements Juan Moreno reviewed a first draft of this paper. The present study was supported by project ANT94-0036 from the Spanish C.I.C.Y.T. (Programa Nacional de Investigación en la Antártida). Transport to and from the island was provided by the Hespérides, Spanish Navy. We gratefully acknowledge the hospitality offered at the Spanish Army Base "Gabriel de Castilla".

\section{References}

Amundsen T (1995) Egg size and early nestling growth in the snow petrel. Condor 97:345-351

Amundsen T, Stokland JN (1990) Egg size and parental quality influence nestling growth in the shag. Auk 107:410-413

Amundsen T, Lorentsen S-H, Tveraa T (1996) Effects of egg size and parental quality on early nestling growth: an experiment with the Antarctic petrel. J Anim Ecol 65:545-555

Bolton M (1991) Determinants of chick survival in the lesser blackbacked gull: relative contributions of egg-size and parental quality. J Anim Ecol 60:949-960

Chandler CR (1995) Practical considerations in the use of simultaneous inference for multiple tests. Anim Behav 49:524-527

Croxall JP, Rothery P, Crisp A (1992) The effect of maternal age and experience on egg-size and hatching succes in wandering albatrosses Diomedea exulans. Ibis 134:219-228

Daan S, Dijkstra C, Drent D, Meijer T (1988) Food supply and the annual timing of avian reproduction. Acta XIX Congressus Internationalis Ornithologici, University of Ottawa Press, Ottawa, Canada pp 392-407

Grant MC (1991) Relationships between egg size, chick size at hatching, and chick survival in the whimbrel Numenius phaeopus. Ibis 133:127-133

Howe HF (1978) Initial investment, clutch size and brood reduction in the common grackle (Quiscalus quiscula L.). Ecology 59:1109-1122

Hoyt DF (1979) Practical methods of estimating volume and fresh egg weight of bird eggs. Auk 96:73-77

Lack D (1947) The significance of clutch size. Ibis 89:302-352

Lamey TC (1990) Hatch asynchrony and brood reduction in penguins. In: Davis LS, Darby JT (eds) Penguin biology. Academic Press, San Diego, pp 399-416
Magrath RD (1992) The effect of egg mass on the growth and survival of blackbirds: a field experiment. J Zool Lond 227:639653

Meathrel CE, Skira IJ, Bradley JS, Wooler RD (1993) The influence of egg-size, mass and composition upon hatching success in the short-tailed shearwater Puffinus tenuirostris (Aves: Procellariiformes). J Zool Lond 230:679-686

Mock DW (1984) Infanticide, siblicide and avian nestling mortality. In: Hausfaster G, Hrdy SB (eds) Infanticide: comparative and evolutionary perspectives. Aldine, New York, pp 3-30

Moreno J, Carrascal LM, Sanz JJ, Amat JA, Cuervo JJ (1994) Hatching asynchrony, sibling hierarchies and brood reduction in the chinstrap penguin Pygoscelis antarctica. Polar Biol 14:2130

Moreno J, Barbosa A, Potti J, Merino S (1997) The effects of hatching date and parental quality on chick growth and creching age in the chinstrap penguin (Pygoscelis antarctica): a field experiment. Auk 114:47-54

Norusis MJ (1992) SPSS for Windows 5.0. SPSS, Chicago, Ill

O'Connor RJ (1978) Brood reduction in birds: selection for fraticide, infanticide, and suicide? Anim Behav 26:79-96

Reid WV, Boersma PD (1990) Parental quality and selection on egg size in the Magellanic penguin. Evolution 44:1780-1786

Rice WR (1989) Analyzing tables of statistical tests. Evolution 43:223-225

Ricklefs RE (1965) Brood reduction in the curve-billed thrasher. Condor 67:505-510

Robertson GJ, Cooke F (1993) Intra-clutch egg size variation and hatching success in the common eider. Can J Zool 71:544-549

Saether B-E (1990) Age-specific variation in reproductive performance of birds. In: Power DM (ed) Current ornithology, vol 7. Plenum Press, New York, pp 251-283)

Schifferli L (1973) The effect of egg-weight on the subsequent growth of nestling great tits Parus major. Ibis 115:549-558

Smith HG, Ottosson U, Ohlsson T (1993) Interclutch variation in egg mass among starlings Sturnus vulgaris reflects female condition. Ornis Scand 24:311-316

Van Heezik YM, Seddon PJ (1991) Influence of hatching order and brood size on growth in jackass penguins. S Afr J Zool 26:199203

Viñuela J, Moreno J, Carrascal LM, Sanz JJ, Amat JA, Ferrer M, Belliure J, Cuervo JJ (1996) The effect of hatching date on parental care, chick growth and chick mortality in the chinstrap penguin Pygoscelis antarctica. J Zool Lond 240:51-58

Williams AJ (1980) Offspring reduction in macaroni and rockhopper penguins. Auk 97:754-759

Williams TD (1994) Intraspecific variation in egg size and egg composition in birds: effects on offspring fitness. Biol Rev 68:35-59

Williams TD, Croxall JP (1991) Chick growth and survival in gentoo penguins (Pygoscelis papua): effect of hatching asynchrony and variation in food supply. Polar Biol 11:197-202

Williams TD, Lank DB, Cooke F, Rockwell RF (1993) Fitness consequences of egg-size variation in the lesser snow goose. Oecologia 96:331-338 